\title{
Fracture Toughness of Concrete by using Recycle Aggregates in Addition with $\mathrm{S}_{2}$ Glass Fiber
}

\author{
Anshul Garg, Nitish Kumar Jha, Pushpendra Kumar Sharma
}

\begin{abstract}
The scarcity in conventional material to prepare concrete and a demand of reuse of demolished or abandoned waste of concrete structure gives a reason to study the ways of using more amount of recycled aggregates. Various studies reviewed the use of recycled aggregates but to a maximum limit of $50 \%$ whereas use glass fibers gave a better response to mechanical and chemical properties of concrete 1. For concrete the occurrence of cracks and pores is uncertain and it is important to investigate whether they are intact or not. The durability of the fracture tests depends on the ductile nature of concrete structures under load. It was found that there is a need to assess the strength of the concrete at fracture of the critical point. The present study aims at finding out how far the ductility of concrete with recycle aggregates can be improved by the addition of S2 glass fibers in terms of fracture toughness by varying the fiber content. The research work consist of replacement of recycle aggregates with five different mixes of concrete as 40, 60, 70, $80 \& 100 \%$ and in each five mixes the addition of S2 glass fiber with $0.25 \%-1 \%$ by its weight with an increment of $0.25 \%$ is done. 3 point bending test on notched beams were conducted for determination of critical stress intensity. The tests were performed as per the guidelines of International Union of Laboratories and Experts in Construction Materials, Systems and Structures (RILEM) 5.The research paper gives idea about optimum percentage of recycle aggregates and $\mathbf{S 2}$ glass fiber that can be used in concrete structures casting taking in account the study of fracture toughness.

Keywords: Fracture Toughness, Critical Stress Intensity, RILEM, Crack propagation, S2 glass fiber
\end{abstract}

\section{INTRODUCTION}

Concrete is for most part versatile material utilized in the turf of structural designing. Reusing concrete is a feasible alternative to enhance the interest on great characteristic assets and breaking point the measure of waste arranged in landfills 2. Estimating the compressive or elasticity just won't ensure the exhibition of the solid structure attributable to the communication of the material conduct, previous splits and geometry of the structure 3 . The solid fracture properties can give more portrayal of the potential burden conveying limit of the material in a given basic system 4 .

Since concrete is a composite material, the nearness of breaks and pores inside cement can't be controlled. So it gets important to research whether these splits are steady or not

Manuscript received on April 02, 2020.

Revised Manuscript received on April 20, 2020.

Manuscript published on May 30, 2020.

* Correspondence Author

Anshul Garg*, School of Civil Engineering, Lovely Professional University, Phagwara, India. Email: anshulgarg2008@gmail.com

Nitish Kumar Jha, School of Civil Engineering, Lovely Professional University, Phagwara, India. Email: jha.nitish@rocketmail.com

Dr. Pushpendra Kumar Sharma*, School of Civil Engineering, Lovely Professional University, Phagwara, India. Email: p.sharmaji10@gmail.com

(C) The Authors. Published by Blue Eyes Intelligence Engineering and Sciences Publication (BEIESP). This is an open access article under the CC BY-NC-ND license (http://creativecommons.org/licenses/by-nc-nd/4.0/)
6. Fracture mechanics is a significant technique for examining solid conduct under static stacking. The fracture execution of reused total cement with expansion of S2 glass fiber has not been assessed to date in the writing and could give further understanding to the material execution when utilized for concrete 7. Research on fracture properties of different solid blends has discovered a noteworthy advantage with expansion of fiber fortification to plain concrete. Most of writing recommends the quality of cement containing reused solid total (RCA) is not exactly coarse total cement even at low water/bond proportions. A few nations have seen the reusing of development and destruction squander as another structure material as one of the primary objectives over terms of reasonable structure conduct 8 . Numerous analysts have submitted their work to depict the properties of reused total, the base necessities for their utilization in concrete and the properties of reused total cement. Past examinations likewise show that glass strands are solid constituents and the utilization of glass filaments prompts an expansion in concrete flexural quality 9. Among the accessible glass fiber, S2 glass fiber has expanded solid quality. The utilization of strengthened cement with reused total S2 glass fiber will consequently have most extreme quality and effectiveness 10 . The goal of this exploration was to initially decide the fracture properties of a regular concrete as contrasted and reuse total cement what's more with S2 glass fiber with comparable blend constituent and degree.

\section{METHODOLOGY}

The experimental study consists of evaluating materials and preparing a regular M25 grade strength concrete with a total aggregate size of $20 \mathrm{~mm}$. S2 glass fibers having an aspect ratio of $150-200$ in volume fractions of $0.25 \%, 0.5 \%$, $0.75 \%$ and $1 \%$ and recycle aggregates with five different mixes as $40,60,70,80 \& 100 \%$ replacement were used for the study. The experimental system consists of a three-point bending test on volume $500 \times 100 \times 100 \mathrm{~mm}$ notched beam samples with an initial $30 \mathrm{~mm}$ notch depth and $3 \mathrm{~mm}$ width for all $400 \mathrm{~mm}$ period mixes and all the test are done as per guidelines of RILEM 5. The details of the specimen for the fracture test are shown in Fig. 1. The deflection was distinguished using dial gauge through testing. 
Fracture Toughness of Concrete by using Recycle Aggregates in Addition with $\mathrm{S}_{2}$ Glass Fiber

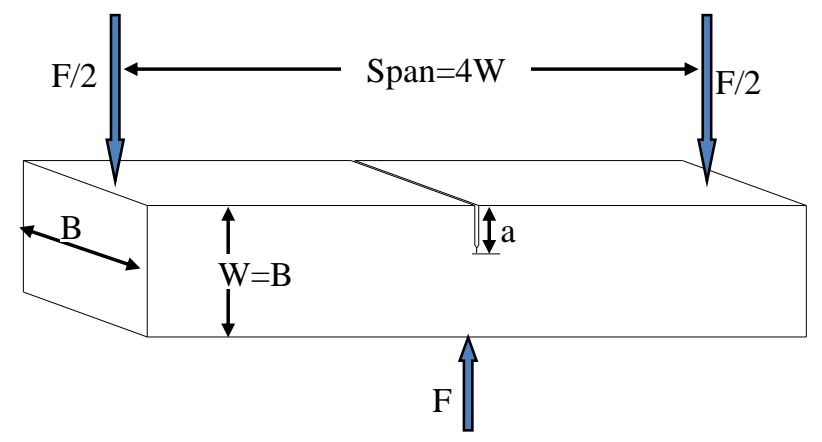

Fig. 1. Details of Fracture Test Specimens

According to the RILEM 5., the fracture toughness is determined using equation (1) as the critical stress intensity Kic.

$$
K i c=\frac{3 F S \sqrt{\pi a}}{2 B W^{2}} f(\alpha)(1)
$$

Where, Kic $=$ critical stress intensity $(\mathrm{MPa} \sqrt{\mathrm{m}}), \mathrm{F}-\max$. load $(\mathrm{N}), \mathrm{S}, \mathrm{W}$ and $\mathrm{B}$ are the span, depth, and width in $\mathrm{mm}$ respectively of the testing beam.

$f(\alpha)$ is geometry factor, which depends on the ratio of the notch depth/crack length (a) to the depth (W) of the beam. In case $\mathrm{S}=4 \mathrm{~W}$ as applied in the current study, $\mathrm{f}(\alpha)$ can be as shown in equation 2.

$$
f(\alpha)=\frac{\left[1.99-\alpha(1-\alpha)\left(2.15-3.93 \alpha+2.7 \alpha^{2}\right)\right]}{\sqrt{\pi}(1+2 \alpha)(1-\alpha)^{1.5}}(2)
$$

The materials utilized for the investigation are Ordinary Portland Cement of Grade 43, locally available river sand utilized as fine aggregates, reused aggregates of demolished structures, coarse aggregates of $20 \mathrm{~mm}$ and S2 glass fiber of $15 \mathrm{~mm}$ length and $0.1 \mathrm{~mm}$ width, Master Glenium B233 as super plasticizer and water of drinking quality.

Table- I: Physical Properties of Cement

\begin{tabular}{|c|c|c|}
\hline Properties & $\begin{array}{c}\text { Data } \\
\text { obtained }\end{array}$ & Standard Data \\
\hline Normal consistency & $33.5 \%$ & $26 \%-33 \%$ \\
\hline Initial setting time & $49 \mathrm{~min}$ & 30 minimum \\
\hline Final setting time & $242 \mathrm{~min}$ & 600 maximum \\
\hline Fineness & $4.65 \%$ & $\leq 10 \%$ \\
\hline Specific gravity & 3.12 & 3.15 \\
\hline
\end{tabular}

Table- II: Physical Properties of Aggregates

\begin{tabular}{|l|c|c|}
\hline Name & $\begin{array}{c}\text { Water } \\
\text { Absorption }\end{array}$ & $\begin{array}{c}\text { Specific } \\
\text { Gravity }\end{array}$ \\
\hline Coarse Aggregates & $0.556 \%$ & 2.69 \\
\hline Fine Aggregates & $0.9 \%$ & 2.59 \\
\hline Recycled Aggregates & $7.92 \%$ & 2.34 \\
\hline
\end{tabular}

Mix design of M25 grade concrete was carried out as per IS 10262-2019 11. Straight type S2 glass fiber with an aspect ratio of 150 was used in the experimental study which has Magnesium alumino silicate glass without $\mathrm{CaO}$. The mix was confirmed based on a slump of $75 \mathrm{~mm}$ and 28 day cube compressive strength of $33.55 \mathrm{MPa}$. The final mix proportions and mix designations are shown in Table III and IV respectively.

\begin{tabular}{|c|c|c|c|c|}
\hline Material & Cement & $\begin{array}{c}\text { Fine } \\
\text { aggregates }\end{array}$ & $\begin{array}{c}\text { Coarse } \\
\text { Aggregates }\end{array}$ & Water \\
\hline $\begin{array}{c}\text { Weight } \\
\left(\mathrm{kg} / \mathrm{m}^{3}\right)\end{array}$ & 435.41 & 736.12 & 1035.29 & 191.6 \\
\hline Ratio & 1 & 1.69 & 2.377 & 0.44 \\
\hline
\end{tabular}

Table- IV: Mix Designations and Percentages of

Materials Added or Replaced in Concrete in $\mathrm{Kg} / \mathrm{m} 3$

\begin{tabular}{|c|c|c|c|}
\hline SN & Description & $\begin{array}{c}\text { \% replacement of } \\
\text { coarse with } \\
\text { recycled aggregates }\end{array}$ & $\begin{array}{c}\text { \% volume } \\
\text { of S2 glass } \\
\text { fiber }\end{array}$ \\
\hline 1 & CR0G0 & 0 & 0 \\
\hline 2 & CR40G0.25 & 40 & 0.25 \\
\hline 3 & CR40G0.5 & 40 & 0.5 \\
\hline 4 & CR40G0.75 & 40 & 0.75 \\
\hline 5 & CR40G1.0 & 40 & 1.0 \\
\hline 6 & CR60G0.25 & 60 & 0.25 \\
\hline 7 & CR60G0.5 & 60 & 0.5 \\
\hline 8 & CR60G0.75 & 60 & 0.75 \\
\hline 9 & CR60G1.0 & 60 & 1.0 \\
\hline 10 & CR70G0.25 & 70 & 0.25 \\
\hline 11 & CR70G0.5 & 70 & 0.5 \\
\hline 12 & CR70G0.75 & 70 & 0.75 \\
\hline 13 & CR70G1.0 & 70 & 1.0 \\
\hline 14 & CR80G0.25 & 80 & 0.25 \\
\hline 15 & CR80G0.5 & 80 & 0.5 \\
\hline 16 & CR80G0.75 & 80 & 0.75 \\
\hline 17 & CR80G1.0 & 80 & 1.0 \\
\hline 18 & CR100G0.25 & 100 & 0.25 \\
\hline 19 & CR100G0.5 & 100 & 0.5 \\
\hline 20 & CR100G0.75 & 100 & 0.75 \\
\hline 21 & CR100G1.0 & 100 & 1.0 \\
\hline
\end{tabular}

\section{A. Casting of Specimens}

The moulds have been fitted for the beam test. For conducting fracture examination, specimens with and without recycled aggregates \& S2 glass fiber are casted. For each combination, two samples were cast i.e. a total of 42 specimens of beams were cast. The samples of concrete beams were left without disruption until a hardened condition was reached. After 2 hours, the notch system was removed and after 24 hrs. the samples were submerged in water for 28 days.

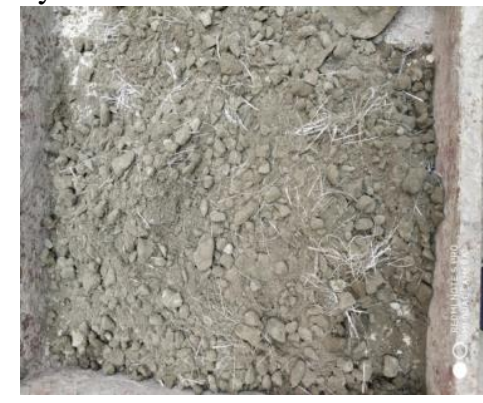

Fig. 2. Concrete Mix with Recycle Aggregates and S2 Glass Fiber 


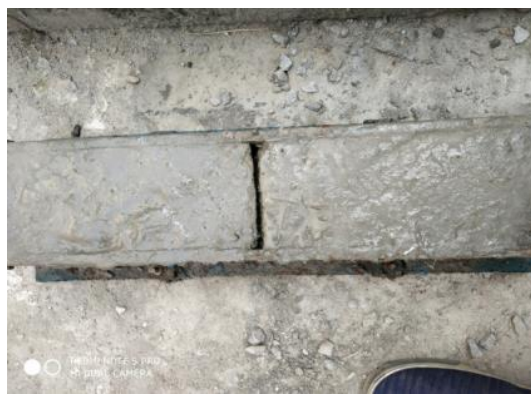

Fig. 3. Notched Beam Specimen for Fracture Test

\section{RESULTS \& DISCUSSIONS}

The specimen was subjected to 3-point bending in simply supported end condition. In order to determine the fracture strength, the 3-point bending tests were performed on beams with 100x100 mm cross section and an effective length of $400 \mathrm{~mm}$. The results of peak load, Crack Length and critical stress intensity are shown in Table V. To represent the behavior of concrete beams due to central load the acquired data is plotted in Fig. 4, 5, 6.

Table- V: Results of Fracture Toughness with Different S2 Glass Fiber and Recycle Aggregate on Concrete

\begin{tabular}{|c|c|c|c|c|}
\hline \multicolumn{5}{|c|}{ Beams } \\
\hline SN & Name & $\begin{array}{c}\text { Peak } \\
\text { Load (N) }\end{array}$ & $\begin{array}{c}\text { Crack } \\
\text { Length "a" } \\
\text { (mm) }\end{array}$ & $\begin{array}{c}\text { Kic } \\
(\mathbf{M P a} \sqrt{ } \mathbf{m})\end{array}$ \\
\hline 1 & CR0G0 & 4550 & 53.03 & 1.59 \\
\hline 2 & CR40G0.25 & 4370 & 54.41 & 1.53 \\
\hline 3 & CR40G0.5 & 4895 & 51.45 & 1.71 \\
\hline 4 & CR40G0.75 & 5715 & 50.85 & 1.99 \\
\hline 5 & CR40G1.0 & 4200 & 55.4 & 1.47 \\
\hline 6 & CR60G0.25 & 4450 & 53.42 & 1.56 \\
\hline 7 & CR60G0.5 & 5575 & 51.97 & 1.94 \\
\hline 8 & CR60G0.75 & 6015 & 50.01 & 2.09 \\
\hline 9 & CR60G1.0 & 4425 & 53.78 & 1.55 \\
\hline 10 & CR70G0.25 & 4150 & 55.73 & 1.45 \\
\hline 11 & CR70G0.5 & 4360 & 54.41 & 1.53 \\
\hline 12 & CR70G0.75 & 4505 & 53.05 & 1.57 \\
\hline 13 & CR70G1.0 & 4100 & 55.39 & 1.44 \\
\hline 14 & CR80G0.25 & 4205 & 54.9 & 1.47 \\
\hline 15 & CR80G0.5 & 4325 & 54.24 & 1.51 \\
\hline 16 & CR80G0.75 & 4350 & 54.08 & 1.52 \\
\hline 17 & CR80G1.0 & 4165 & 55.06 & 1.46 \\
\hline 18 & CR100G0.25 & 3575 & 64.35 & 1.26 \\
\hline 19 & CR100G0.5 & 3600 & 62.28 & 1.27 \\
\hline 20 & CR100G0.75 & 3750 & 60.36 & 1.32 \\
\hline 21 & CR100G1.0 & 3700 & 60.96 & 1.30 \\
\hline
\end{tabular}

Fracture robustness increased with S2 glass fiber content with $60 \%$ recycled aggregate replacement and attained a maximum value for $0.75 \%$ fiber content and then decreased. With the introduction of S2 glass fibers, ductility was found to be improved and CR60G0.75 was found to be more ductile. The improvement in ductility was due to the active particle binding and containment. Flexural failure was the pattern of failure observed. Plain concrete beams failed by dividing into 2 halves, whereas GFRC beams only showed narrow cracks and no splitting. The results showed that the overall load and fracture capacity of GFRC beams were significantly increased relative to plain concrete beams.

\section{CONCLUSION}

The M25 grade concrete mix has been built with a total $20 \mathrm{~mm}$ aggregate volume. The effect of fiber content on concrete's fresh properties has been studied. The study's main goal was to investigate the effect of S2 glass fibers with recycled aggregates on the behavior of concrete beam fractures.

1. The application of S2 glass fiber in a concrete mix affects the fresh properties of concrete and requires a dosage of $0.25 \%-0.45 \%$ super plasticizer to keep the fresh properties within workable limits.

2. With 60 percent recycled aggregates and $0.75 \%$ fiber material, the ultimate load was improved by 32.2 percent and fracture strength by 31.45 percent relative to normal concrete beams.

3. There was a significant increase in the critical load and the fracture parameters of GFRC beams compare to plain concrete beams.

4. The fracture behavior of RAC and traditional concrete is identical under the same degree of concrete grade. If the RCA's replacement ratio is more than $60 \%$, the strength of the fracture will be decreased by a total of $20 \%$.

5. By including S2 glass fibers, the mode of failure was changed from brittle to ductile flexural process.

\section{ACKNOWLEDGMENTS}

The authors acknowledge the support from the School of Civil Engineering, Lovely Professional University for providing laboratory to perform these tests.

\section{REFERENCES}

1. A. Garg and P. K. Sharma, "A Critical Review on Behaviour of Glass Fiber Reinforced Concrete Using Recycled Aggregates," IOSR Journal of Engineering, vol. 1 (Special), 2019, pp. 54-59.

2. Z.P. Bazant, "Concrete fracture models: testing and practice," Engineering fracture mechanics, vol. 69, 2002, pp. 165-205.

3. F. Bencardino, L. Rizzuti, G. Spadea, and R. N. Swamy, "Experimental evaluation of fibre reinforced concrete fracture properties," Cement and concrete composites, vol. 41(B), 2010, pp $17-24$

4. M. Elices, C. G. Rocco, "Effect of aggregate size on the fracture and mechanical properties of a simple concrete," Engineering Fracture Mechanics, vol. 75, 2008, pp. 3851-3889.

5. RILEM 50-FMC, "Determination of fracture energy of mortar and concrete by means of three point bending test on notched beams,' Materials and structures, vol. 18, 1985, pp. 285-290.

6. R. Ince and K. E. Alyamac, "Determination of fracture parameters of concrete based on water-cement ratio," Indian journal of engineering and Material sciences, vol. 15, 2008, pp. 14-22.

7. J. D. Brito, F. Alves, "Concrete with recycled aggregates: the Portuguese experimental research," Materials and Structures, vol. 43, 2010, pp. 35-51. 
8. E. Denneman, R. Wu, A. T. Visser, "Discrete fracture in high performance fibre reinforced concrete materials," Engineering Fracture Mechanics, vol. 78, 2011, pp. 2235-2245.

9. D. Zhang, T. Ueda, "Fracture mechanisms of polymer cement mortar: concrete interfaces," Journal of engineering mechanics, vol. 139, 2013, pp. 167-176.
10. G. J. Kumari, P. J. Rao and M. V. S. Rao, "Behaviour of concrete beams reinforced with glass fiber reinforced polymer flats," International journal of research in engineering and technology, vol. 2, no. 09, 2013, pp. 202-208.

11. IS: 10262-2019, "Recommended guide lines for concrete mix design," Bureau of Indian Standards, New Delhi.

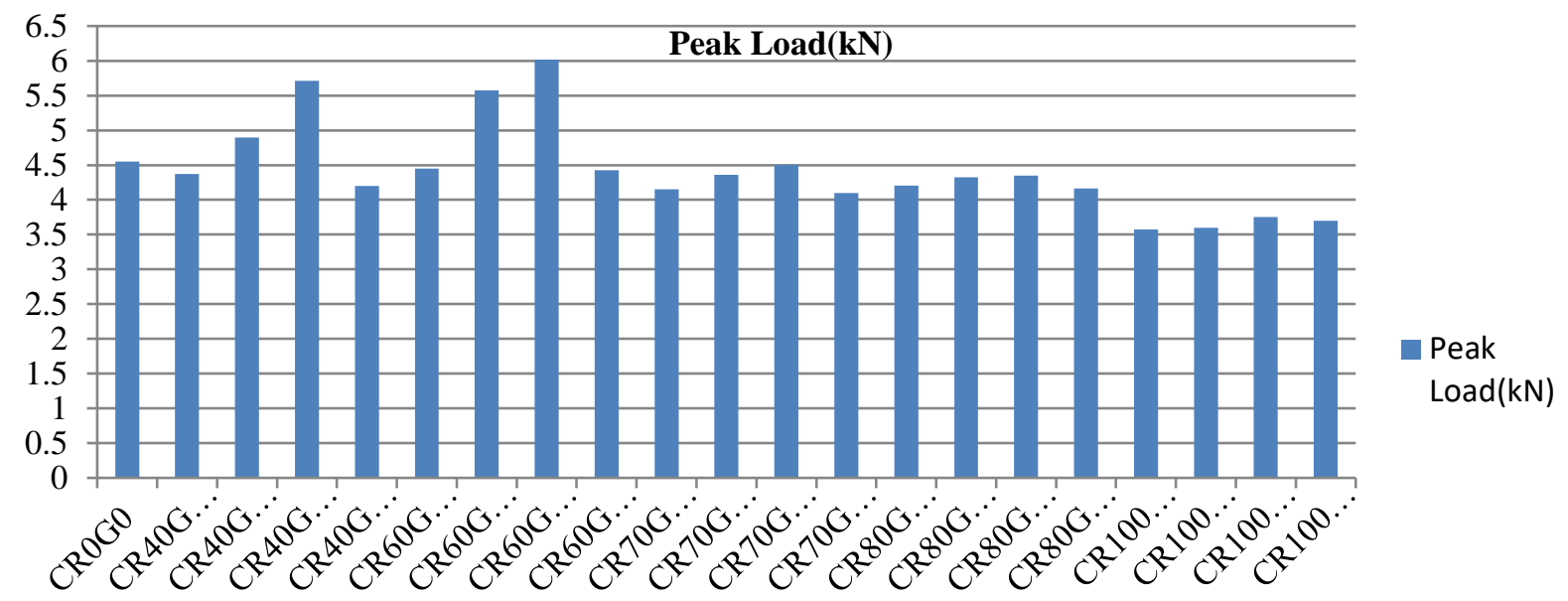

Fig. 4. Peak Loads for All Specimens

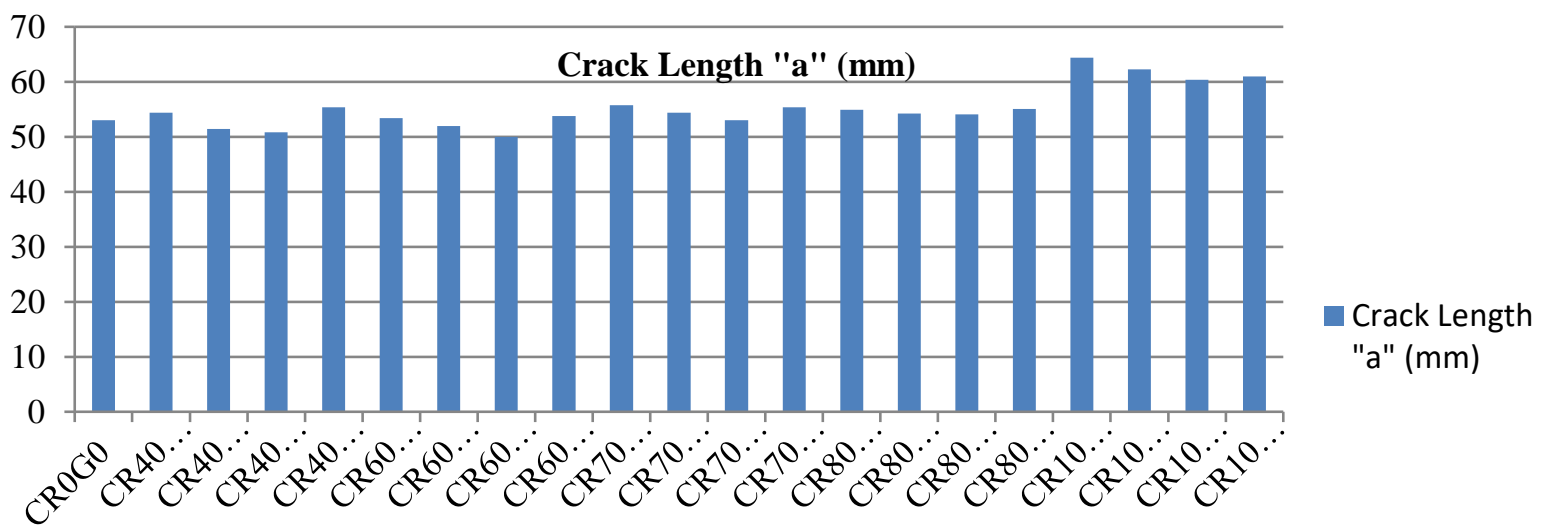

Fig. 5. Crack Length for All Specimens

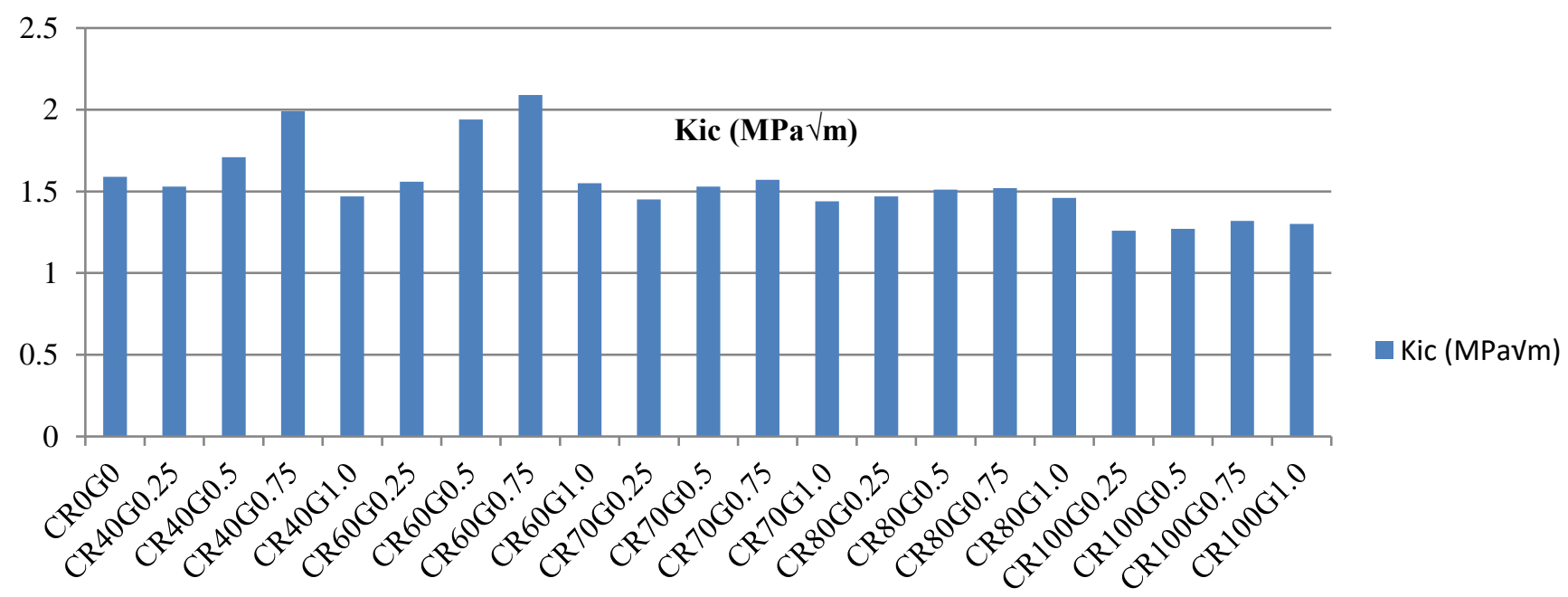

Fig. 6. Critical stress intensity of all test specimens 


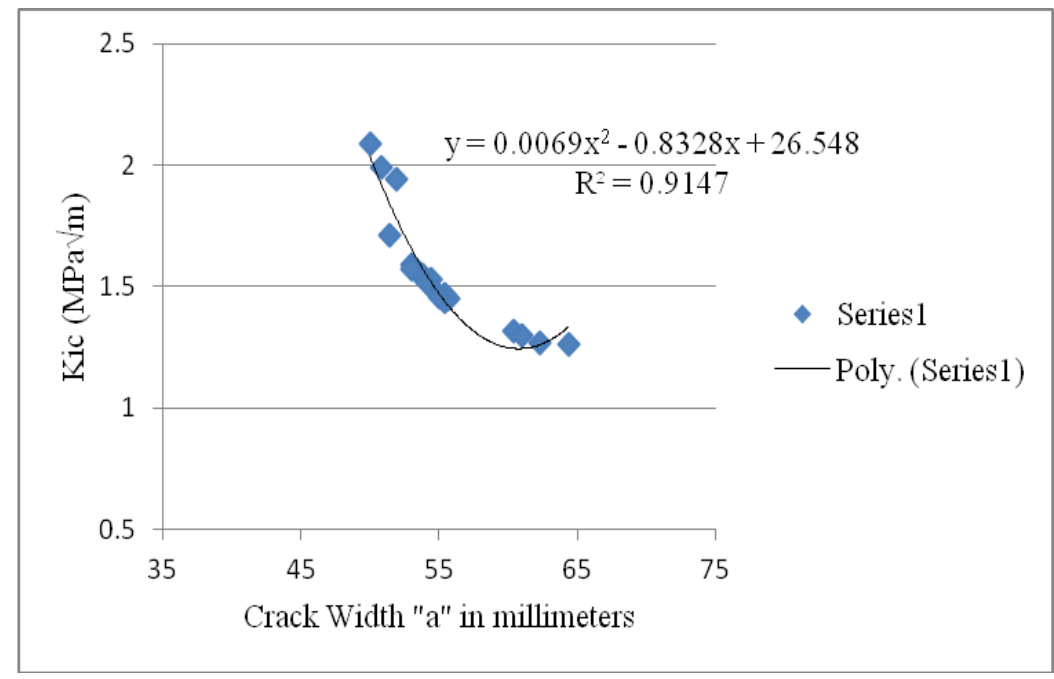

Fig. 7. Kic vs Crack Length (mm) and Regression Equation of All Test Specimens

\section{AUTHOR'S PROFILE}

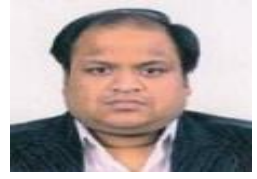

Anshul Garg, born in March 1983, Graduated from Institute of Engineering \& Technology, Khandari, Agra affiliated to Dr. Bhimrao Ambedkar University, Agra in field of Civil Engineering in 2006 and Post Graduated from Manipal University, Karnataka in field of Structural Engineering in 2009 is presently pursuing Ph.D from Lovely Professional University, Phagwara, Punjab and is Assistant Professor in School of Civil Engineering, Lovely Professional University, Phagwara, Punjab, India. He is having a total experience of more than 11 years; 2.5 years construction industry and 8.5 years of teaching. $\mathrm{He}$ is having his areas of interest in Concrete Technology, Analyses of Structures, Design of Reinforced Concrete and Steel Structures, Earthquake Resistant Design of Structures etc. He has been the author of more than 10 International/ Conference research papers.

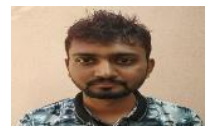

Nitish Kumar Jha, born in July 1992, Graduated from Nepal Engineering College ,Bhaktapur, Nepal in field of Civil Engineering in 2015 and Post graduation in Business Studies from Tribhuwan University, Nepal in 2018, is a research scholar currently enrolled in M.Tech Structural Engineering in School of Civil Engineering, Lovely Professional University, Phagwara, Punjab, India. He is having a total experience of more than 2 years in construction industry. His areas of interests are light weight structures, earthquake resistant structures, water supply \& sanitation, structural design. He is life time member of Nepal Engineering Council.

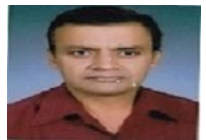

Dr. Pushpendra Kumar Sharma, born in December 1963, Graduated and Post Graduated from Aligarh Muslim University, Aligarh, India in field of Civil Engineering in 1996 and with the same Research centre completed $\mathrm{PhD}$ in Civil Engineering with Specialization in Environmental and Water Resources Engineering in 2016, is a Professor in School of Civil Engineering, Lovely Professional University, Phagwara, Punjab, India. He is having a total experience of more than 28 years; 9.5 years construction industry and 20 years of teaching. He is having his areas of interests like Environmental and Water Resources, Green Buildings, Capacity buildings, earthquake resistant buildings, energy efficient buildings, water and wastewater treatment technologies, environmental designs, sustainable construction project management, river pollution control and industrial wastewater treatment etc.
Dr. Pushpendra Kumar Sharma in addition to teaching has served and officiated many administrative designation like Dean Academics, Dean Students Welfare, Warden, Chairman Construction Committee HCST etc. He has been the author of more than 60 International/Conference research papers. He is reviewer of Cogent Engineering International Journal of Tailor and Francis, Journal of Environmental Chemical Engineering and has reviewed many papers of the same. He has successfully organized National and International Conferences in the working institutions. He is life time member of Indain Molecular Society (IMS), Indian Science Congress Association (ISCA) and Institution of Engineers, India (IEI). Currently he is guiding 8 PhDs in Civil Engineering on various topics @ LPU. He has guided one M.Tech and two more currently being guided in LPU. He has guided 150 B.Tech level projects on various topics of Civil Engineering. He has filed 8 patents out of which One recommended and one published and rest in pipe line. He attended many workshops of international and national repute. He is successfully trained under National Programme for Capacity Building of Engineers in Earthquake Risk Management (NPCBEERM), organized by Department of Civil Engineering, Indian Institute of Technology, Madras. 